\title{
FETAL ANGIOTENSIN RECEPTOR BLOCKERS EXPOSURE - NEONATAL OUTCOME -
}

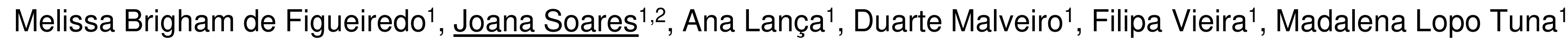 \\ 1 - Unidade de Neonatologia, Serviço de Pediatria, Centro Hospitalar de Lisboa Ocidental; 2 - Centro Hospitalar de Leiria
}

\section{BACKGROUND AND AIMS}

In utero exposure to renin-angiotensin-aldosterone system inhibitors, as angiotensin receptor blockers (ARBs), is associated with an increased risk of adverse fetal effects. Most common complications are related to impaired fetal renal function, including anuria and renal failure, resulting in oligohydramnios with consequent pulmonary hypoplasia, skeletal deformations and limb contractures. Other adverse outcomes include hypotension, hypocalvaria, cerebral malformations, miscarriage and perinatal death.

\section{CASE REPORT}

\section{PREGNANCY}

- 35 year-old mother with chronic hypertension

- Treated with olmersartan and hydrochlorothiazide for the previous 6 months

- Unknown pregnancy until 3 days before delivery

- Estimated gestational age 31 weeks and 3/7 days

- Severe oligohydramnios

\section{DELIVERY}

- Cesarian section, female newborn, Apgar scores 6/8/9

- Somatometry in the $50^{\text {th }}-90^{\text {th }}$ centile for estimated gestational age (birth weight $1695 \mathrm{~g}$ )

\section{EVOLUTION}

- Dysmorphic features (large fontanelles and limb defects)

- Acute respiratory distress requiring invasive ventilation

- Pulmonary hypoplasia

- Renal ultrasound $\rightarrow$ normal size kidneys with poor parenchymal differentiation

- Anuria, anasarca, intractable hypotension and hypoxemia regardless of maximal respiratory and cardiovascular support

- Death 22 hours after birth

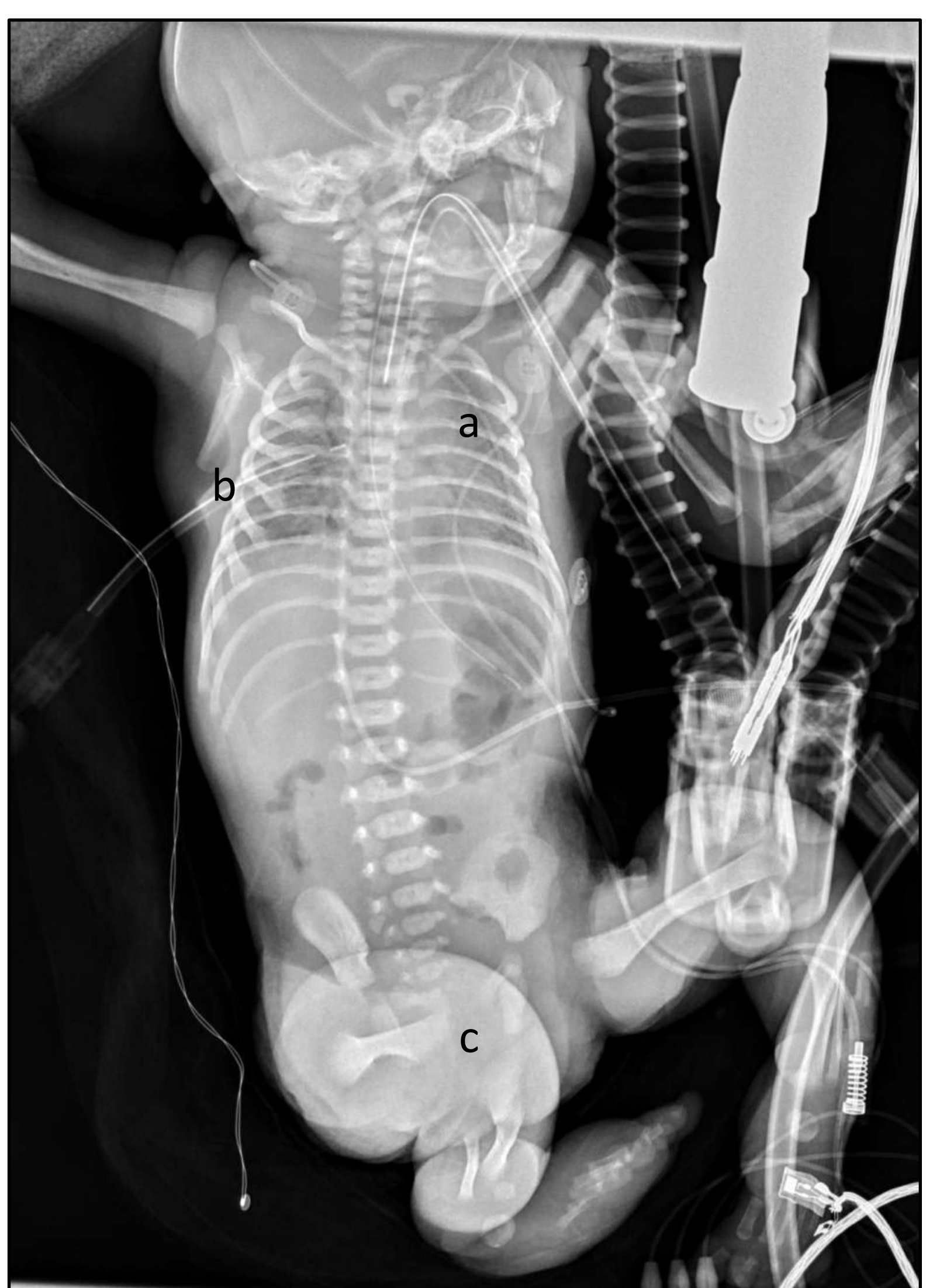

Figure 1. Small lungs with diffuse opacification (a) and chest tube on the right due to pneumothorax (b); right inferior limb contractures (c).

\section{CONCLUSIONS}

As other cases reported in the literature, exposure to ARBs during an unknown pregnancy lead to a fatal outcome. This group of drugs is contraindicated during gestation and, in order to increase awareness of its deleterious effects, fetotoxicity outcomes must be reported. In childbearing age women without effective contraceptive methods other antihypertensive agents should be considered. 